\title{
Study in Silico Alkaloid Compounds Tapak Dara Plant (Catharanthus roseus (L) G. Don) on Antiapoptosis Receptor B-Cell Lymphoma-2 Regulator (Bcl-2) as Anti-Cancer Chronic Lymphocytic Leukemia (CLL)
}

\author{
$1^{\text {st }}$ Ahmad Kamal Sudrajat ${ }^{1}, 2^{\text {nd }}$ Maisuna Kundariati ${ }^{1}$ \\ \{kamalsudrajat2@gmail.com $\left.{ }^{1}\right\}$ \\ State University of Malang, Department of Biology, Faculty of Mathematics and Science, Malang, \\ Indonesia $^{1}$
}

\begin{abstract}
Tapak Dara plant (Catharanthus roseus (L) G. Don) has five potential alkaloid compounds as anticancer compounds. This study aims to determine the potential of alkaloid as an anticancer Chronic Lymphocytic Leukemia (CLL) with B-Cell lymphoma2 receptor (Bcl-2). The method of this research is in silico. The compounds used are, vinblastine, vincristine, vindensine, vinflunine, and vinorelbine as well as chlorambucil (leukeran), prednisone, and venetoclax control compounds. The receptor used is B-Cell lymphoma-2 (Bcl-2) with a 2O2F PDB code. The docking process is done with PyRx software. The affinity binding value of vinblastine $(-7.2 \mathrm{kcal} / \mathrm{mol})$, vincristine $(-3.2$ $\mathrm{kcal} / \mathrm{mol})$, vindensine $(-3.6 \mathrm{kcal} / \mathrm{mol})$, vinflunine $(-7.2 \mathrm{kcal} / \mathrm{mol})$, vinorelbine $(-7.1$ $\mathrm{kcal} / \mathrm{mol})$, chlorambucil $(-6.0 \mathrm{kcal} / \mathrm{mol})$, prednisone $(-8.0 \mathrm{kcal} / \mathrm{mol})$, and venetoclax $(-9.2$ $\mathrm{kcal} / \mathrm{mol})$. The amiso acid residues that have similarities with the control compound are on vinflunine (Glu133, Asp108, Phe109, Phe150, Phe147); vinorelbine (Asp108, Gly142, Phe150, Phe147, Phe109); and vinblastine (Ser133). The five vinca alkaloids are predicted to be effective as anticancer Chronic Lymphocytic Leukemia (CLL), namely vinflunine, vinorelbine, and vinblastine.
\end{abstract}

Keywords: Catharanthus roseus (L) G. Don; Bcl-2; Alkaloid; Chronic Lymphocytic Leukemia; Apoptosis, Docking

\section{Introduction}

Tapak dara (Catharantus roseus (L) G. Don) is one plant that is widely distributed in the tropics including the family Apocynaceae. The spread of this plant is very broad in Indonesia so it has various regional names. The virgin can grow in the lowlands to the highlands with an altitude of 800 meters above sea level [1]. Tapak dara (Catharanthus roseus (L) G. Don) is a type of plant used by the community as a traditional medicine.

Various studies that have been carried out have found that the Catharanthus roseus (L) G. Don contain active chemicals that can be used as raw materials for medicines. This plant is identified as containing 130 bioactive ingredients [1]. Some contents of active compounds are catharantine, vinblastine, vincristine, vindoline, and catharoseumine [1]. Vinblastine and vincristine have been known to be used as cancer drugs extracted from the leaves of Catharanthus roseus (L) G. Don [2]. Catharanthus roseus (L) G. Don contains vinblastine, vincristine, leurosine, catharanthine, and lochanerine alkaloids which are efficacious as 
anticancer [3]. According to Yusransyah, Pratiwi, \& Khaerunnisa (2016), Catharantus roseus (L) G. Don have alkaloid compounds namely vincristine, vinorelbine, vinflunine, vinblastine, and vindensine [4].

Chronic Lymphocytic Leukemia (CLL) is the result obtained (not present at birth) from mutations (changes) of DNA (genetic material) from the spinal cord cells that develop into lymphocytes [5]. Leukemia has various types, including Chronic Lymphocytic Leukemia (CLL), Acute Lymphoblastic Leukemia (ALL), Chronic Myeloid Leukemia (CML), and Acute Myeloid Leukemia (AML) [6]. Leukemia is a cancer of white blood cells and starts in the spinal cord and blood, then this cancer will spread throughout the body including the brain [7]. Chronic Lymphocytic Leukemia (CLL) is a type of leukemia that originates from lymphocytes called B-cells [8]. CLL as a blood cancer, can spread throughout the body including lymph nodes, spinal cord, and other organs [9]. CLL is characterized by proliferation and accumulation of CD5-positive cells in the blood, spinal cord, and lymph nodes [10]. It has been reported, in CLL the capacity to produce clonal B cells is obtained in Hematopoietic Stem Cells (HSC) [11]. CLL can be initiated by loss or increase in chromosomal material, such as delesi 13q, deletion 11q, and trisomy 12 followed by mutations and more aggressive leukemia [12].

$\mathrm{Bcl}-2$ is a B-cell lymphoma/leukemia-2 and a second protein from various proteins found in lymphoma [13]. As the name implies, this gene was discovered due to its involvement in Bcell malignancy, where chromosomal translocation occurs which then activates most of the genes in non-Hodgkin's B cell follicular lymphoma [13]. Protein B-cell lymphoma-2 (Bcl-2) is a regulator of the apoptosis process [14]. Bcl-2 is coded by the BCL2 gene derived from follicular lymphoma as a translocation protein on chromosomes number 14 and 18 [15]. This protein is located in the mitochondria, smooth endoplasmic reticulum and perinuclear membrane of blood cells [15]. Bcl-2 expression has been reported in hematologic malignancy [16].

Apoptosis is one of the main mechanisms of cell death in cancer therapy [17]. Apoptosis is often associated with programmed cell death [18]. Apoptosis involves the role of mitochondria, mitochondrial organelles have two groups of $\mathrm{Bcl}-2$ proteins [19]. Unlike most oncogenes as proliferation promoters, $\mathrm{Bcl}-2$ has the function of preventing cell death [20]. The B-Cell lymphoma-2 (Bcl-2) gene is first known in folucular B-cell lymphoma as the gene that regulates the chain of immunoglobulin bonds in the transliter breakpoints [21]. Bcl-2 protein was found to inhibit cell death. Genesis tumors can be caused not only by unlimited cell proliferation, but also by apoptotic disorders [22].

\section{Methods}

\subsection{Preparation of Protein Macromolecul}

Bcl-2 anti-apoptosis is a protein that plays a role in cell apoptosis. Apoptosis is one of the keys to cancer treatment. Bcl-2 gene expression is known in hematologic malignance, one of them is Chronic Lymphocytic Leukemia, which is one type of leukemia that attacks blood cells. Drug compounds that are often used in the treatment of Chronic Lymphocytic Leukemia (CLL) are venetoclax, prednisone, and chlorambucil (leukeran). The initial step is to prepare the target protein and ligand to be used. A two-dimensional protein structure can be downloaded from bank data proteins with the site http://www.rscb.ord/. The selected 
antiapoptotic Bcl-2 receptor identity is $2 \mathrm{O} 2 \mathrm{~F}$. Macromolecules are sterilized using the PyMol application.

\subsection{Ligan Preparation}

The ligand used can be downloaded from PubChem with the site http://PubChem.ncbi.nlm.nih.gov with the .sdf format. Ligan is converted to .pdb format using the Discovery Studio 2016 Client application. The ligands used were five alkaloid compounds from the Tapak Dara plant (Catharantus roseus (L) G. Don) namely vinblastine, vincristine, vindensine, vinflunine, and vinorelbine. While control compounds are drug compounds that have been proven to be a drug for Chronic Lymphocytic Leukemia (CLL) diseases, namely venetoclax, prednisone, and chlorambucil (leukeran).

\subsection{Analysis and Visualization of Docking Results}

The results of bond energy scores on the five alkaloid ligands by docking method using PyRx application are vinblastine $(-7.2 \mathrm{kcal} / \mathrm{mol})$, vincristine $(-3.2 \mathrm{kcal} / \mathrm{mol})$, vindensine $(-3.6$ $\mathrm{kcal} / \mathrm{mol})$, vinflunine $(-7.2 \mathrm{kcal} / \mathrm{mol})$, vinorelbine $(-7.1 \mathrm{kcal} / \mathrm{mol})$. And comparative ligands are chlorambucil $(-6.0 \mathrm{kcal} / \mathrm{mol})$, prednisone $(-8.0 \mathrm{kcal} / \mathrm{mol})$, and venetoclax $(-9.2 \mathrm{kcal} / \mathrm{mol})$.

\section{Result}

Testing ligand test of alkaloid compounds and comparative ligands on Bcl-2 antiapoptotic receptors was carried out using PyRx application. The position of Alkaloid LigandsComparison Ligand (Venetoclax) can be seen in Figures 1, 2, 3, 4, and 5.

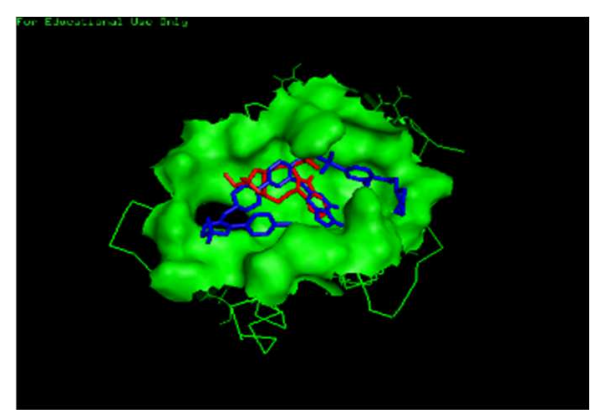

Figure 1. Vinblastine-Venetoclax 


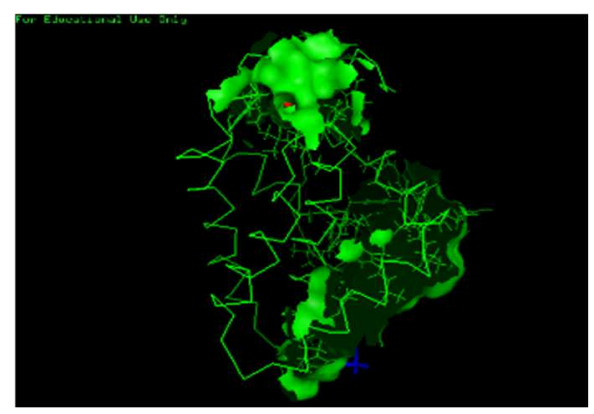

Figure 2. Vincristine-Venetoclax

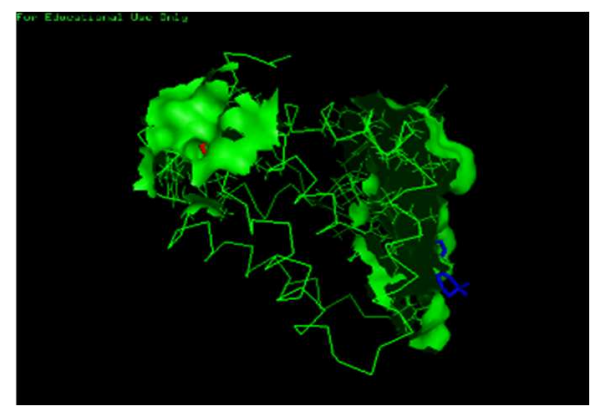

Figure 3. Vindensine-Venetoclax

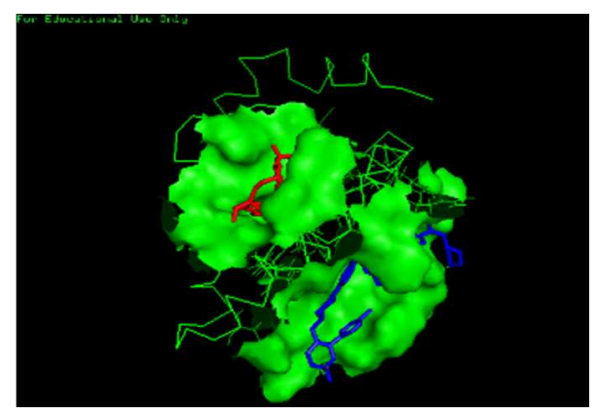

Figure 4. Vinflunine-Venetoclax 


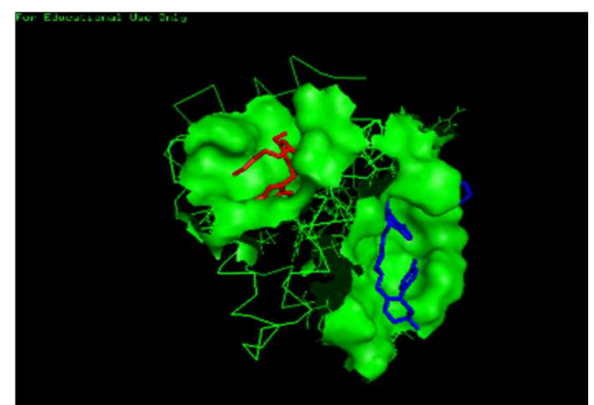

Figure 5. Vinorelbine-Venetoclax

The position of Alkaloid Ligands-Comparison Ligand (Prednisone) can be seen in Figures 6, 7, 8, 9, and 10 .

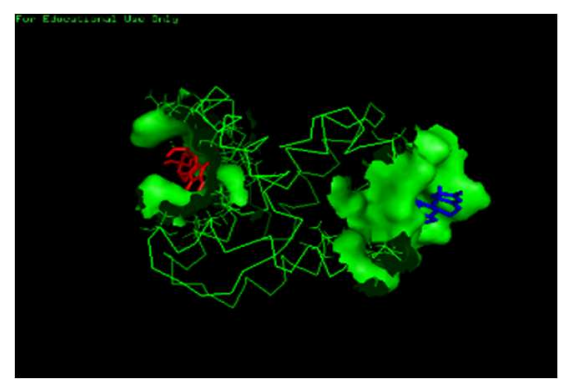

Figure 6. Vinblastine-Prednisone

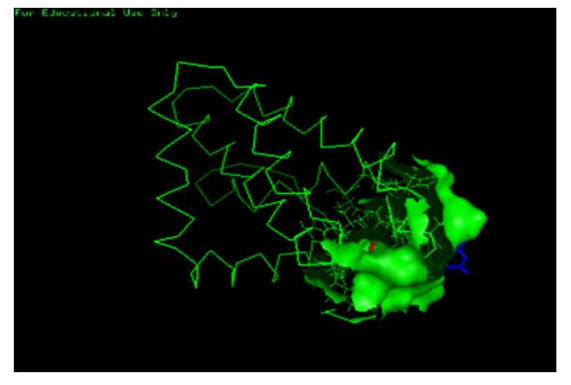

Figure 7. Vincristine-Prednisone 


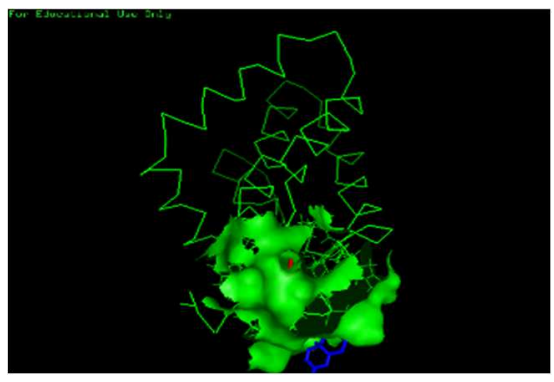

Figure 8. Vindensine-Prednisone

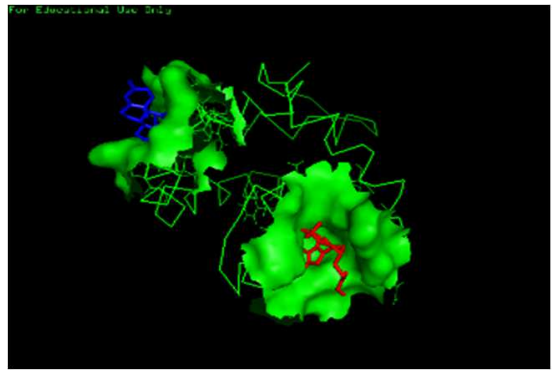

Figure 9. Vinflunine-Prednisone

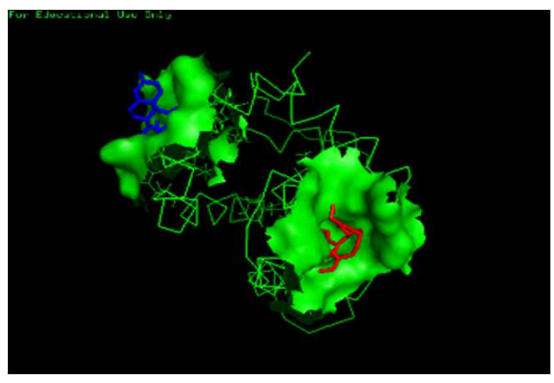

Figure 10. Vinorelbine-Prednisone

The position of Alkaloid Ligands-Comparison Ligand (Chlorambucil) can be seen in Figures 11, 12, 13, 14, and 15 . 


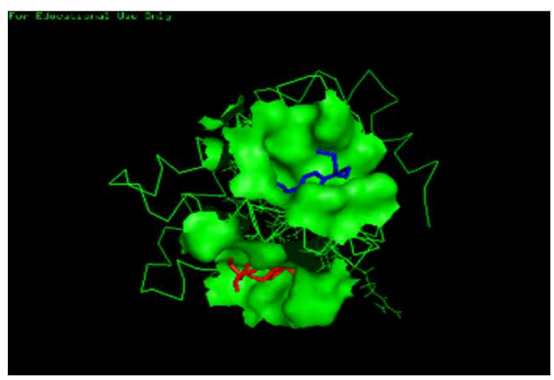

Figure 11. Vinblastine-Chlorambucil

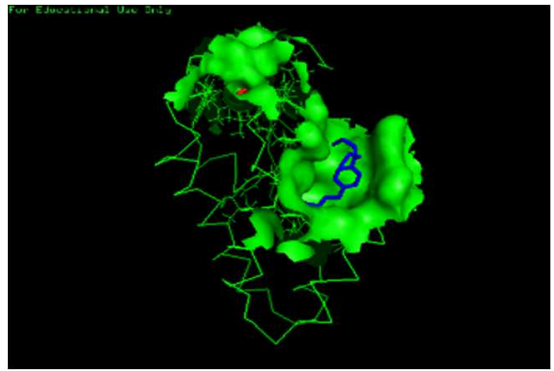

Figure 12. Vincristine- Chlorambucil

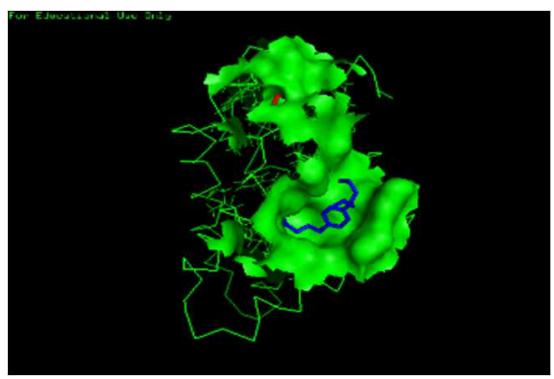

Figure 13. Vindensine- Chlorambucil 


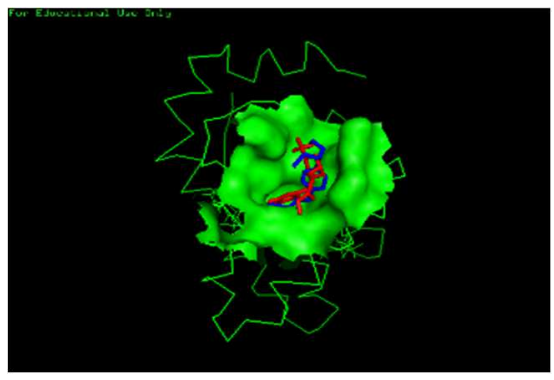

Figure 14. Vinflunine- Chlorambucil

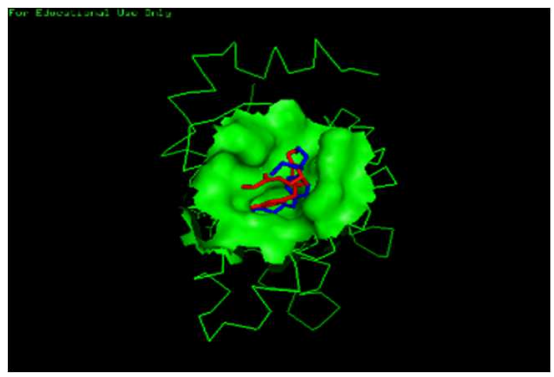

Figure 15. Vinorelbine- Chlorambucil

From the results of visualization of the binding sites of alkaloid ligands with comparative ligands it is known that vinblastine has the same inherent side as the comparative ligand venetoclax, vinflunine and vindensine have the same inherent side as the comparative ligand chlorambucil. Based on the interaction of Bcl-2 antiapoptotic amino acid residues, Table 1 shows residual amino acids.

Table 1. Residual Amino Acids 


\begin{tabular}{llllllll}
\hline \multicolumn{3}{c}{ Catharanthus roseus (L) G. Don Compounds } & \multicolumn{3}{c}{ Control Compounds } \\
\hline vinblastine & vincristine & vindensine & vinflunine & vinorelbine & chlorambucil & prednisone & Venetoclax \\
\hline SER A:114 & ALA & ASN & GLU & ASP A:108 & PHE A:147 & GLN & ASN \\
SER A:113 & A:194 & A:189 & A:133 & GLY A:142 & VAL A:130 & A:187 & A:160 \\
GLN A:23 & TRP & ILE A:186 & ASP & PHE A:150 & LEU A:134 & ASP A:8 & TYR A:19 \\
PHE A:109 & A:141 & ASN & A:108 & PHE A:147 & PHE A:150 & GLY & ARG A:95 \\
& ASN & A:140 & PHE & PHE A:109 & GLU A:133 & A:190 & ARG \\
A:189 & PHE & A:101 & & MET A:112 & GLY & A:103 \\
PHE & A:195 & PHE & & PHE A:109 & A:191 & GLU \\
A:195 & TRP & A:109 & & ASP A:108 & & A:157 \\
TRP & A:192 & PHE & & TYR A:105 & & SER A:113 \\
A:192 & & A:150 & & GLY A:142 & & HIS A:117 \\
TRP & & PHE & & ARG A:143 & & ASN \\
A:185 & & A:147 & & & & A:160 \\
& & & & & &
\end{tabular}

\section{Discussion}

Most patients who experience CLL experience high sensitivity to treatment [23]. Treatment given to CLL sufferers such as chemotherapy or other treatments can cause complications in CLL patients or even make the cancer worse [12], [24]. The thing that causes CLL to get worse is because of the interaction between CLL cells and other cell types, such as stromal cells, $\mathrm{T}$ cells and nurse-like cells in the lymph node [6]. One solution offered to handle CLL sensitivity is to use herbal plants. Based on the results of research, herbs have few side effects than commercially made chemical drugs [25]-[27]. Based on this, researchers conducted an analysis of the content of the Catharanthus roseus (L) G. Don plant which can be used as an alternative to the CLL drug.

Based on the results of data analysis there are 2 compounds that have many similarities amino acid residues so that it can be used as a BCL-2 activator that functions in cell apoptosis. The two compounds contained in Catharanthus roseus (L) G. Don are Vinflunine and Vinorelbine. There have been previous studies on the plant Catharanthus roseus (L) G. Don has examined the effects of these plants on apoptosis of cancer cells [28]. This research was conducted by Yusransyah et al., (2016) conducted to test the efficacy of breast cancer [4]. The results of his study showed no effect on vetiver plants against breast cancer apoptosis. In Malaysia the Catharanthus roseus (L) G. Don is believed to be used as a traditional cancer drug [29].

There are 3 different mechanisms for apoptosis-experienced cells, namely: (1) apoptosis originating from signals in cells (via mitochondrial pathways), (2) apoptosis due to the stimulation of death activators that bind to cell surface receptors namely TNF, and (3) Neurons and other cells have different paths unlike the previous 2 paths (without caspase) [18]. However, each cell has a different mechanism in apoptosis [30].

\section{Conclusion}

Based on data analysis and discussion, Catharanthus roseus (L) G. Don plant is most likely to be used as a natural substitute for CLL drugs. The active compound in Catharanthus roseus (L) G. Don which can be used as anti-cancer is Vinflunine and Vinorelbine. This research is still in the stage of estimating the effects of a compound through computational 
estimates, further research is recommended to do testing in the laboratory whether the active compound contained in Catharanthus roseus (L) G. Don can actually be used as a CLL drug.

Acknowledgements. This paper in conjuction with the 9th International Conference On Green Technology (ICGT) 2018.

\section{References}

[1] N. L. Watiniasih, P. Sudiarta, and N. S. Antara, "Praktek Baik Budidaya Tanaman Tapak Dara (Catharanthus roseus (Linn.) Don)." Universitas Udayana, Bali, 2012.

[2] I. M. Chung et al., "Screening 64 cultivars Catharanthus roseus for the production of vindoline, catharanthine, and serpentine," Biotechnol. Prog., vol. 27, no. 4, pp. 937-943, 2011.

[3] L. P. devi Dinata, "Formulasi Tablet Ekstrak Herba Tapak Dara Leonindita Perdana Devi Dinata Fakultas Farmasi," Universitas Muhammadiyah Surakarta, 2009.

[4] Yusransyah, D. Pratiwi, and L. Khaerunnisa, "Study in Silico Compound of Interest Vinca Alkaloids Of (Catharanthus Roseus (L) G. Don) Estrogen Receptor Beta as Anticancer Breast," Farmagazine, vol. III, no. 2, pp. 16-20, 2016.

[5] J. R. Brown, "Inherited predisposition to chronic lymphocytic leukemia.," Expert Rev. Hematol., vol. 1, no. 1, pp. 51-61, 2008.

[6] T. J. Kipps et al., "Chronic lymphocytic leukaemia," Nat. Rev. Dis. Prim., vol. 3, no. 16096, pp. 1-22, 2017.

[7] PDQ Adult Treatment Editorial Board, Adult Acute Lymphoblastic Leukemia Treatment (PDQ®): Patient Version. National Cancer Institute (US), 2002.

[8] P. Ghia and F. Caligaris-Cappio, "The Origin of B-Cell Chronic Lymphocytic Leukemia," Semin. Oncol., vol. 33, no. 2, pp. 150-156, 2006.

[9] D. A. Shead, L. J. Hanisch, R. Clarke, and A. Corrigan, "Chronic Lymphocytic Leukemia," 2018.

[10] C. Rozman and E. Montserrat, "Chronic Lymphocytic Leukemia," N. Engl. J. Med., vol. 333, no. 16, pp. 1052-1057, 1995.

[11] Y. Kikushige et al., "Self-Renewing Hematopoietic Stem Cell Is the Primary Target in Pathogenesis of Human Chronic Lymphocytic Leukemia," Cancer Cell, vol. 20, no. 2, pp. 246-259, 2011.

[12] D. A. Landau et al., "Mutations driving CLL and their evolution in progression and relapse," Nature, vol. 526, no. 7574, pp. 525-530, 2016.

[13] A. Rahman, "Diagnosis dan Penatalaksanaan Limfoma Orbita," $M K A$, vol. 37, no. 2, pp. 30 37, 2014.

[14] D. T. Chao and S. J. Korsmeyer, "BCL-2 FAMILY : Regulators of Cell Death," Annu. Rev. Immunol, vol. 16, no. 1, pp. 395-419, 1998.

[15] Y. Tsujimoto, L. R. Finger, J. Yunis, P. C. Nowell, and C. M. Croce, "Cloning of the chromosome breakpoint of neoplastic B cells with the $\mathrm{t}(14 ; 18)$ chromosome translocation," Science (80-. )., vol. 226, no. 4678, pp. 1097-1099, 1984

[16] J. C. Reed and M. Pellecchia, "Review in translational hematology Apoptosis-based therapies for hematologic malignancies," Blood, vol. 106, no. 2, pp. 408-418, 2005.

[17] N. N. Danial and S. J. Korsmeyer, "Cell Death: Critical Control Points," Cell, vol. 116, no. 2, pp. 205-219, 2004.

[18] R. Y. Corvianindya and R. Joelijanto, "Jalur molekuler," Jurmal Kedokt. Gigi Univ. Indones., vol. 10, no. Edisi Khusus, pp. 69-73, 2003. 
[19] C. Wang and R. J. Youle, "Role of mitochondria in apoptosis," Exp. Physiol., vol. 88, no. 1, pp. 85-90, 2003.

[20] D. L. Vaux and A. Strasser, "The Molecular Biology of Apoptosis [Review]," Proc. Natl. Acad. Sci. U. S. A., vol. 93, no. 6, pp. 2239-2244, 1996.

[21] L. Impera et al., "A novel fusion $5^{\prime} \mathrm{AFF} 3 / 3$ 'BCL2 originated from a $\mathrm{t}(2 ; 18)(\mathrm{q} 11.2 ; \mathrm{q} 21.33)$ translocation in follicular lymphoma," Oncogene, vol. 27, no. 47, pp. 6187-6190, 2008.

[22] F. Tzifi, C. Economopoulou, D. Gourgiotis, A. Ardavanis, S. Papageorgiou, and A. Scorilas, "The role of BCL2 family of apoptosis regulator proteins in acute and chronic leukemias," $A d v$. Hematol., vol. 2012, 2012.

[23] M. A. Anderson et al., "The BCL2 selective inhibitor venetoclax induces rapid onset apoptosis of CLL cells in patients via a TP53-independent mechanism," Blood, vol. 127, no. 25, pp. 32153224, 2016.

[24] G. D. te Raa and A. P. Kater, "TP53 dysfunction in CLL: Implications for prognosis and treatment," Best Pract. Res. Clin. Haematol., vol. 29, no. 1, pp. 90-99, 2016.

[25] M. Ekor, "The growing use of herbal medicines: Issues relating to adverse reactions and challenges in monitoring safety," Front. Neurol., vol. 4 JAN, no. January, pp. 1-10, 2014.

[26] A. Karimi, M. Majlesi, and M. Rafieian-Kopaei, "Herbal versus synthetic drugs; beliefs and facts.," J. nephropharmacology, vol. 4, no. 1, pp. 27-30, 2015.

[27] Y. S. Pathare and V. D. Wagh, "Herbal medicines and nutritional supplements used in the treatment of glaucoma: A review," Res. J. Pharm. Biol. Chem. Sci., vol. 3, no. 1, pp. 331-339, 2012.

[28] R. N. Kulkarni, K. Baskaran, and T. Jhang, "Breeding medicinal plant, periwinkle [Catharanthus roseus (L) G. Don]: A review," Plant Genet. Resour. Characterisation Util., vol. 14, no. 4, pp. 283-302, 2016.

[29] S. Das and A. B. Sharangi, "Madagascar periwinkle (Catharanthus roseus L.): Diverse medicinal and therapeutic benefits to humankind," J. Pharmacogn. Phytochem., vol. 6, no. 5, pp. 1695-1701, 2017.

[30] S. Mishra, "A Biotechnological Approach to Apoptosis in Living Organism: An Overview," Sci. Int., vol. 8, p. 282298, 2013. 